24 Smith WC. Are hypersensitivity reactions to dapsone becoming more frequent? Lepr Rev 1988;59:53-8

25 Grayson ML, Yung AP, Doherty RR. Severe dapsone syndrome due to weekly Maloprim. Lancet 1988; ; 531 .

26 Ferone R. Antimalarial drugs. II. In: Handbook of experimental pharmacology 68/II. Peters W, Richards WH, eds. Berlin: Springer-Verlag, 1985.

27 Cutting W. Antifertility effects of biguanides. Antibiot Chemother 1962;12: 671-5.

28 Anonymous. Pyrimethamine combinations in pregnancy. Lancet 1983;ii: $1005-7$

29 Von Hengst P. Untersuchungen zur Teratogenität des Daraprim (pyrimethamin) beim Menschen. Zentrabl Gynakol 1972;94:551-5.

30 Bruce-Chwatt LJ. Màlaria and pregnancy. Br Med F 1983;286:1457-8.

31 Scholer HJ. Assessment of the safety of Fansidar to pregnancy. Animal and human data. Geneva: World Health Organisation, 1983. (MAP/SGPM/ INF83.6.)

32 Bohni E, Fust B, Rieder J, Schaerer K, Havas I. Comparative toxicological, chemotherapeutic and pharmacokinetic studies with sulphormethoxine and other sulphonamides in animals and men. Chemotherapy 1969;14:195-226.

33 Barbosa JC, Ferreira I. Sulfadoxine-pyrimethamine (Fansidar) in pregnan women with toxoplasma antibody titers. In: Siegenthaler $\mathbf{W}$, Luethy $\mathbf{R}$ eds. Current Chemotherapy. Proceedings of the Xth international congress of chemotherapy. Zurich: American Society of Microbiology 1978:134-5.

34 Maurus JN. Hansen's disease in pregnancy. Obstet Gynecol 1978;52:22-5.

35 Spencer HC, Watkins WM, Sixsmith DG, Koech DK, Chulay JD. A new in vitro test for pyrimethamine/sulfadoxine susceptibility of Plasmodium falciparum and its correlation with in vivo resistance in Kenya. Bull WHO 1984;62:615-21.

36 Pinchepongse S, Doberstyn EB, Cullen JR, Yisunri L, Thongsombun Y, Thimasaran K. An evaluation of five regimens for the out-patient therapy of falciparum malaria in Thailand. Bull WHO 1982;60:907-12.

(Accepted 25 April 1990)
University Hospital, Queen's Medical Centre, Nottingham NG7 2UH

L G H Jacobs, FRCSED, research fellow department of orthopaedic and accident surgery

M A Pringle, FRCGP, senior lecturer department of general practice

Correspondence to: Mr Jacobs.

\title{
Referral letters and replies from orthopaedic departments: opportunities missed
}

\author{
L G H Jacobs, M A Pringle
}

\begin{abstract}
Objective-To study delays between sending referral letters and the outpatient appointment and to assess the content of referral and reply letters, their educational value, and the extent to which questions asked are answered by reply letters.

Design-Retrospective review of referrals to 16 consultant orthopaedic surgeons at five hospitals, comprising 288 referral letters with corresponding
\end{abstract} replies, by scoring contents of letters.

Setting-Orthopaedic teaching hospitals in Nottingham, Derby, and Mansfield.

Main outcome measures-Weighted scores of contents of referral and reply letters, assessment of their educational value, and responses to questions in referral letters.

Results-Median outpatient delay was 23.4 weeks. There was no significant decrease in waiting time if the referral letter was marked "urgent" but a significantly greater delay $(p<0.01)$ if referrals were directed to an unnamed consultant. The content score was generally unsatisfactory for both referrals and replies, and there was no correlation for the content scores of the referral letter and its reply $(r=0 \cdot 13)$. Items of education were rare in the referral letters $(8 / 288 ; 3 \%)$ and significantly more common in replies $(75 / 288 ; 26 \%)(p<<0.001)$. Senior registrars were significantly more likely to attempt education than other writers $(p<0 \cdot 02)$. Education in replies was significantly related to increased length of the letter $(p<0.05)$ and was more likely to occur if the referral was addressed to a named consultant $(p<0.03) .48$ (17\%) Referral letters asked questions, of which 21 (44\%) received a reply. No factor was found to influence the asking of or replying to questions.

Conclusions - The potential for useful communication in the referral letter and in the reply from orthopaedic surgeons is being missed at a number of levels. The content is often poor, the level of mutual education is low, and the use of the referral letter to determine urgency is deficient. Most questions asked by general practitioners are not answered.

\section{Introduction}

Although there is evidence of improvement in the content of referral letters, ${ }^{12}$ Hull and Westerman reported in 1986 that $27 \%$ of referral letters to a medical department were barely adequate or else absent or poor. ${ }^{3}$ Partly as a response, standardisation of the contents of referral letters for each specialty has been suggested. ${ }^{146}$ Further problems with the referral process lie in the considerable delays between referral and the outpatient visit and in the omission of important details from the hospital replies, which rarely answer questions posed by general practitioners in their referral letters. ${ }^{7-9}$

Traditionally, doctors obtain continuing medical education from postgraduate meetings and medical journals. Other potential sources are professional correspondence, the lay press, pharmaceutical representatives, informal meetings with professional colleagues, and patients. Letters are important in "the educative role of consultants" and as a medium for "the process of mutual education." It could therefore be asked whether and to what extent general practitioners receive education in replies from orthopaedic surgeons in response to their referral letters; whether those general practitioners in most need of such education (as indicated by poor content of the referral letter) receive it most often; and whether general practitioners impart any education regarding the patients they refer.

Studies have analysed the contents (but not the educational potential) of letters for general medical and psychiatric referrals, ${ }^{156}$ but no studies have examined orthopaedic referrals and their replies. Thus the aims of this study were to assess: the delay between writing the referral letter and the outpatient appointment; the content of the referral letters from general practitioners to orthopaedic surgeons and their associated replies; the extent to which mutual education occurs between general practitioners and orthopaedic surgeons and the factors that influence such education; and the extent to which questions asked by referral letters are answered in the reply.

\section{Method}

Referrals to elective outpatient clinics of 16 consultant orthopaedic surgeons at Nottingham General Hospital, City Hospital (Nottingham), Mansfield District General Hospital, Harlow Wood Orthopaedic Hospital (near Mansfield), and the hand surgery unit at Derby Royal Infirmary were reviewed retrospectively. The letters from the first 20 new patients attending each consultant's clinic after 1 October 1988 were used. The referral letter(s) and all replies from orthopaedic surgeons to the general practitioner in the month after the patient was seen were photocopied. Any details identifying authors were coded and then removed before assessment. 
Letters were assessed in four ways.

(1) Generally - Legibility, author's status, addressee, dates of referral and clinic appointment, and length of the letter in lines were recorded.

(2) Content-If there was more than one letter of referral or reply, all were taken into account. Items of text were either present or absent and those present were given a weighted score depending on their importance in an orthopaedic context.

(3) Education - In this study education was defined as extra information in the form of an adjective (for example, "typical"), phrase, or sentence that qualified a description of the patient's examination, management, or diagnosis and that the recipient could transfer or apply to another patient. It included information that could increase the recipient's understanding of the problem itself (not just a diagnostic label), its implications for patients in general or their environment, the problems and options in management (not just a description of the management schedule recommended), or the prognosis expected.

(4) Responses to questions asked-All questions (direct or indirect) in the referral letter were counted and compared with the reply letter. Any attempt to answer a question in the reply was recorded.

\section{STATISTICAL ANALYSIS}

The level of agreement between observers for the presence or absence of a scored item in a letter was calculated as a $x$ value; $>0.75$ was accepted as a good level of agreement. ${ }^{10}{ }^{11}$ Fifty pairs of letters were scored by both of us ( $x$ values $0 \cdot 77-1 \cdot 0$ ); the rest of the letters were then scored by only one of us. Results were analysed with the $\chi^{2}$ test, Student's unpaired $t$ test, and regression program of the Statistical Package for Social Studies, with significance set at $\mathbf{p}<0.05$.

TABLE I - Status of writers of referral letters to orthopaedic outpatient department and of writers of replies

\begin{tabular}{lr|lr}
\hline Writer of letter & $\begin{array}{c}\text { No }(\%) \\
(\mathbf{n}=289)\end{array}$ & Writer of reply & $\begin{array}{r}\text { No }(\%) \\
(\mathbf{n}=289)\end{array}$ \\
\hline Principal & $279(96 \cdot 5)$ & Consultant & $143(49 \cdot 7)$ \\
Assistant & $3(1 \cdot 0)$ & Senior registrar & $69(23 \cdot 9)$ \\
Trainee & $5(1 \cdot 7)$ & Registrar & $65(22 \cdot 6)$ \\
Locum & $1(0 \cdot 3)$ & Senior house officer & $11(3 \cdot 8)$ \\
Unknown & $1(0 \cdot 3)$ & Unknown & $1(0 \cdot 3)$ \\
\hline
\end{tabular}

TABLE II - Type of hospital reply letter

\begin{tabular}{lr}
\hline & $\begin{array}{c}\text { No }(\%) \\
(\mathbf{n}=289)\end{array}$ \\
\hline Letter & $132(45 \cdot 7)$ \\
Copy of clinical note & $147(50 \cdot 9)$ \\
Copy of tertiary referral & $3(1 \cdot 0)$ \\
Copy of clinical note and letter & $6(2 \cdot 1)$ \\
None & $1(0 \cdot 3)$ \\
\hline
\end{tabular}

\section{Results}

Of the 320 pairs of letters obtained, 31 (9\%) were interconsultant referrals, leaving 289 pairs for the analysis. One referral and one reply letter were missing from two sets of correspondence. There were thus 288 letters in each group. Tables I and II show the status of the authors and types of reply written. All patients were referred with elective orthopaedic conditions, and there were no fractures. Referrals were made for opinions regarding $27(9 \%)$ possible hip or knee joint replacement operations, 41 (14\%) back problems, 82 $(29 \%)$ neck and arm problems, and $138(48 \%)$ other leg problems.

\section{DELAYS}

The median delay between referral and the first clinic appointment was 164 days (range 1-472 days). In all, $160(56 \%)$ letters had no indication of urgency, 81 $(28 \%)$ letters were marked "routine," and 47 (16\%) letters were labelled "urgent." There was no significant decrease in waiting time for patients whose referral letters were labelled "urgent" compared with those labelled "routine" (mean (95\% confidence interval) 155 (111 to 189) $v 176$ (150 to 202) days), but letters referred to an unnamed consultant ("Dear doctor,") resulted in a significantly longer waiting time than letters referred to a named consultant (227 (184 to 270) $v 168$ (154 to 182 ) days; $\mathrm{p}<0.01$ ).

\section{CONTENTS OF REFERRAL AND REPLY LETTERS}

Table III shows the rates of occurrence for items of content in the referral letter and their counterparts in the reply. The median content scores were 4 (range 1-10) for the referral letters (maximum 29) and 5 (1-11) for the replies (maximum 22). The $x$ values show that the presence of an item in the referral letter had no influence over the occurrence of its counterpart in the reply. This was further confirmed by the poor correlation $(r=0 \cdot 13)$ of content scores for referral letters and their respective hospital replies. There was no significant difference between scores for replies to referral letters with a score $\leqslant 3$ and those with a score $>3$ $(32 / 122(26 \%) v 41 / 166(25 \%))$. The content of letters written by junior doctors was significantly better than that of letters written by consultants, but there was no difference in content if the reply was the copy of the clinical note (table IV).

\section{EDUCATIONAL VALUE}

Only eight (3\%) general practitioner referral letters had any educational value, according to our definition. This was significantly less than the 75 (26\%) reply letters that had education in at least one aspect $\left(\chi^{2}=63.2 ; p<<0.001\right)$. Education in the reply was not significantly different whether this was a standard letter or a copy of the clinical note $(29 / 132(22 \%) v$

TABLE III - Items of text present (with weighted values) in referral and reply letters ( $n=288$ )

\begin{tabular}{|c|c|c|c|c|c|c|}
\hline Referral item & $\begin{array}{l}\text { Weighted } \\
\text { score }\end{array}$ & $\begin{array}{c}\text { No }(\%) \text { of } \\
\text { letters }\end{array}$ & Reply item & $\begin{array}{l}\text { Weighted } \\
\text { score }\end{array}$ & $\begin{array}{c}\text { No }(\%) \text { of } \\
\text { letters }\end{array}$ & $\begin{array}{c}x \\
\text { Value }\end{array}$ \\
\hline Urgency indicated & 3 & $130(45 \cdot 1)$ & Follow up indicated & * & $257(89 \cdot 2)$ & -0.06 \\
\hline Referral reason & 3 & $271(94 \cdot 1)$ & Diagnosis given & 3 & $236(81 \cdot 9)$ & 0.06 \\
\hline History of problem & 2 & $152(52 \cdot 8)$ & History of problem & 1 & $122(42 \cdot 4)$ & $0 \cdot 17$ \\
\hline Past treatment of problem & 3 & $95(33 \cdot 0)$ & Past treatment of problem & 1 & $44(15 \cdot 3)$ & $0 \cdot 21$ \\
\hline Past medical history & 1 & $77(26 \cdot 7)$ & Past medical history & 1 & $46(16.0)$ & $0 \cdot 25$ \\
\hline Social history & 2 & $68(23 \cdot 6)$ & Social history & 1 & $74(25 \cdot 7)$ & $0 \cdot 16$ \\
\hline Family history & 1 & $11(3 \cdot 8)$ & Family history & 1 & $11(3 \cdot 8)$ & $0 \cdot 15$ \\
\hline Examination findings & 2 & $172(59 \cdot 7)$ & Examination findings & 2 & $228(79 \cdot 2)$ & $0 \cdot 00$ \\
\hline Special investigations & 3 & $103(35 \cdot 8)$ & Special investigations & 3 & $154(53 \cdot 3)$ & $0 \cdot 24$ \\
\hline Patient given information & 2 & $9(3 \cdot 1)$ & Patient given information & 3 & $69(24 \cdot 0)$ & 0.05 \\
\hline List of present medication & 3 & $79(27 \cdot 4)$ & Change in medication & 1 & $10(3.5)$ & 0.03 \\
\hline Steroid injection given & 1 & $5(1 \cdot 7)$ & Steroid injection given & 2 & $17(5.9)$ & 0.07 \\
\hline Surgery performed & 1 & $1(0 \cdot 3)$ & Listed for surgery & * & $83(28 \cdot 8)$ & -0.01 \\
\hline Other management & 2 & $33(11 \cdot 4)$ & Other management & $\star$ & $122(42 \cdot 4)$ & $0 \cdot 02$ \\
\hline Maximum possible score & 29 & & Maximum possible score & 22 & & \\
\hline
\end{tabular}

„If any of these items were mentioned the reply letter scored 3 in the "follow up" category. 
TABLE IV-Content of reply letters written by consultants and junior doctors

\begin{tabular}{|c|c|c|c|c|}
\hline & \multicolumn{2}{|c|}{ Standard letter } & \multicolumn{2}{|c|}{ Copy of clinical note } \\
\hline & Consultants & Juniors & Consultants & Juniors \\
\hline \multicolumn{5}{|c|}{ Content score: } \\
\hline$\leqslant 3$ & 41 & 13 & 9 & 8 \\
\hline$>3$ & 43 & 35 & 44 & 85 \\
\hline $\begin{array}{l}\chi^{2} \\
\mathrm{p} \text { Value }\end{array}$ & \multicolumn{2}{|c|}{$11 \cdot 3$} & \multicolumn{2}{|c|}{$\begin{array}{c}2.2 \\
>0.05\end{array}$} \\
\hline
\end{tabular}

TABLE $\mathrm{v}-$ Educational value of reply letters related to their length

\begin{tabular}{lc}
\hline & $\begin{array}{c}\text { Mean length (lines) } \\
\text { (95\% confidence interval) }\end{array}$ \\
\hline $\begin{array}{l}\text { Standard letter: } \\
\quad \text { Containing education }\end{array}$ & $9 \cdot 1(8 \cdot 1 \text { to } 10 \cdot 1)^{\star}$ \\
$\quad$ Not containing education & $7 \cdot 2(6 \cdot 4$ to $8 \cdot 0)$ \\
Copy of clinical note & \\
$\quad$ Containing education & $20 \cdot 9(17 \cdot 5 \text { to } 24 \cdot 3)^{\star \star}$ \\
$\quad$ Not containing education & $16 \cdot 3(15 \cdot 5$ to $17 \cdot 1)$ \\
\hline
\end{tabular}

${ }^{\star} \mathrm{p}<0.05,{ }^{\star \star} \mathrm{p}<0.01$ for pairs (Student's $t$ test)

TABLE VI-Relation of occurrence of education in reply letter to status of writer

\begin{tabular}{llr}
\hline & \multicolumn{2}{c}{ Education } \\
\cline { 2 - 3 } Writer of reply & Yes & No \\
\hline Consultant & 38 & 105 \\
Senior registrar & 26 & 43 \\
Registrar & 10 & 55 \\
Senior house officer & 11 &
\end{tabular}

$\chi^{2}=13.05 ; \mathrm{df}=3 ; \mathrm{p}<0.005$

43/147 (29\%); $\left.\chi^{2}=4.97, \mathrm{df}=3 ; \mathrm{p}>0.05\right)$. Education was influenced significantly by the length of the reply letter irrespective of the format (standard letter or clinical note copy) (table V). Education in replies was significantly more likely to occur in response to referral letters to named than to unnamed consultants $(71 / 254$ $(28 \%) v 3 / 34(9 \%) ; \chi^{2}=4 \cdot 8$, with Yates's correction; $\mathrm{p}<0.03)$. The occurrence of education was also influenced by the status of the replier (table VI). Partitioning of the $\chi^{2}$ table showed that senior registrars were significantly more likely to educate than consultants, registrars, and senior house officers together $\left(26 / 69(38 \%) v 48 / 220(22 \%) ; \chi^{2}=6.4\right.$ with Yates's correction; $\mathrm{p}<0 \cdot 02)$. Education in the hospital's reply was significantly associated with a higher weighted content score when it did occur than when it did not (mean $4 \cdot 8(4 \cdot 4$ to $5 \cdot 2) v 4 \cdot 3(4 \cdot 1$ to 4.5$) ; \mathrm{p}<0.04)$.

The occurrence of education was not influenced by whether the referral letter was handwritten or typed $(14 / 62(23 \%) v 60 / 226(27 \%))$. Asking questions or not also had no significant effect on the occurrence of education in the reply $(16 / 49(33 \%) v 59 / 239(25 \%))$.

\section{QUESTIONS ASKED AND REPLIED TO}

Forty eight $(17 \%)$ referral letters asked one or more questions, of which $21(44 \%)$ received a reply in the hospital letter. There was no significant difference between consultants and the junior doctors who replied to the general practitioners' questions $(13 / 143(9 \%) v$ $8 / 137(6 \%)$ ). The content score of the replies was not significantly related to whether or not a question in the referral letter received a reply, nor were educating replies more likely than non-educating replies to be given to questions in the referral letter $(9 / 76(11 \cdot 8 \%) v$ $12 / 212(5 \cdot 7 \%))$.

\section{Discussion}

The median delay (23.4 weeks) at the end of 1988 represents a long outpatient waiting time in national terms. ${ }^{12}$ This delay was significantly lengthened if patients were referred to an unnamed consultant. The fact that patients were not seen sooner if the referral letter was marked "urgent" represents a gap in understanding by general practitioners of what problems orthopaedic surgeons believe should be seen urgently or a lack of its appreciation by the orthopaedic surgeon when reading the letter. Consensus between general practitioners and orthopaedic surgeons should be reached on the meaning of "urgent"-including its application to non-clinical factors-by discussion and appropriate postgraduate education.

Half of the hospital consultations were performed by junior doctors; in a study from a district general hospital with no senior registrars $42 \%$ of consultations were with junior doctors. ${ }^{13}$ It should be noted that juniors, in particular senior registrars, wrote letters with better content and with more attempts to educate. The content of both referral and reply letters was generally unsatisfactory as assessed by their scores. Computerisation of the referral letter writing process as described by Preece ${ }^{14}$ would seem to be a satisfactory solution for writing referral letters based on information stored in a database (general practitioner's details, patient's details, medical history, family and social background, allergies, present medication). This would allow the referrer to concentrate on the present problem and the reason for referral.

General practitioners seldom attempt to educate their orthopaedic colleagues. They may think that to do so would be a presumption. We believe, however, that such education is usually appropriate-for example, to explain the effect of the patient's problem on the work he or she does; the social impact of the problem (housing, disability payments, unemployment allowances, etc); the psychological effects on the patient or family; and any reasons for "urgency."

In conclusion, these results show that the considerable delay in the orthopaedic outpatient waiting time was influenced in this study only by writing to a named consultant rather than to the department in general. Both the reasons for and the quality of communications between general practitioners and orthopaedic surgeons were called into question. The use of the referral letter and its reply as an educational conduit was poor; no special attempt was made to focus the education that does occur on those general practitioners who write the referral letters with the lowest score. This together with the apparent indifference to urgent referrals and the lack of response to questions asked leads us to suggest that the referral letter is poorly read in the clinic. The low content scores for most referral letters and replies are either a cause or effect of the low esteem in which this communication seems to be held. There are therefore good grounds for suggesting a rethink of the whole referral correspondence cycle and for making use of the educational opportunity it presents.

We thank Dr J Pearson, department of community medicine and epidemiology, for his help with the $x$ values and the medical records staff at the Queen's Medical Centre and City Hospital, Nottingham; Mansfield General Hospital; Harlow Wood Orthopaedic Hospital, Mansfield; and Derby Royal Infirmary.

1 De Alarcon R, Hodson JM. Value of the general practitioner's letter. A further study in medical communication. Br Med $\mathcal{F} 1964$;ii:435-8.

2 Dowie R. General practitioners and consultants - a study of outpatient referrals London: King Edward's Hospital Fund for London, 1983.

3 Hull FM, Westerman RF. Referral to medical outpatients department at teaching hospitals in Birmingham and Amsterdam. Br Med $\mathcal{J}$ 1986;293 $311-4$.

4 Marinker M, Wilkin D, Metcalfe DHM. Referral to hospital: can we do better? Br.Med J 1988;297:461-4.

5 McMullan JJ, Barr A. Outpatient letters. A study in communication. $7 R$ Coll Gen Pract 1964:7:66-75.

Pullen IM, Yellowlees AJ. Is communication improving between general practitioners and psychiatrists? BrMed f 1985;290:31-3. 
7 De Alarcon $\mathrm{R}$, de Glanville $\mathrm{H}$, Hodson JM. Value of the specialist's report. Br Med f 1960;ii: 1663-4.

terions and relationships between general practicioners and hospital medical staff. London: King Edward's Hospital Fund for London, 1970.

9 Bado W, Williams CJ. Usefulness of letters from hospitals to general practitioners. Br Med f 1984;288:1813-4.

10 Cohen J. A coefficient of agreement for nominal scales. Education and

Psychological Measurement 1960;20:37-46.
11 Fleiss JL. Statistical methods for rates and proportions. 2nd ed. New York: John Wiley and Sons, 1981.

12 Yates J, Wood K. Outpatient waiting time. Birmingham: Inter-Authority Comparisons and Consultancy, Health Services Management Centre, 1985.

13 Kiff RS, Sykes PA. Who undertakes the consultations in the outpatient department? BrMed F 1988;296:1511-2.

14 Preece J. A referral letter in 15 to 20 seconds. Refer 1989;1 (No 10): 12-13.

(Accepted 19 fune 1990)

\title{
Adrenaline and nocturnal asthma
}

\author{
J F J Morrison, C Teale, S B Pearson, P Marshall, N M Dwyer, S Jones, H G Dean
}

Pulmonary Function Laboratory, Killingbeck Hospital, Leeds LS14 6UH

J F J Morrison, MD, senior medical registrar

C Teale, MRCP, tutor in medicine

S B Pearson, FRCP, consultant physician

P Marshall, MB, senior medical house officer

N M Dwyer, MB, senior medical house officer

$\mathrm{S}$ Jones, $\mathrm{MB}$, senior medical house officer

H G Dean, PHD, lecturer in

pharmacology

Correspondence to:

Dr J F J Morrison, 86 Main

Street, Great Gidding,

Huntingdon,

Cambridgeshire PE17 5NU.

BrMed f 1990;301:473-6
Abstract

Objective-To determine whether the nocturnal fall in plasma adrenaline is a cause of nocturnal asthma.

Design-Double blind placebo controlled crossover study. In the first experiment the nocturnal fall in plasma adrenaline at $\mathbf{4}$ am was corrected in 10 asthmatic subjects with an infusion of adrenaline after parasympathetic blockade with $30 \mu \mathrm{g} / \mathrm{kg}$ intravenous atropine. In the second experiment 11 asthmatic subjects showing similar variations in peak expiratory flow rate had the nocturnal fall in plasma adrenaline corrected by infusion before atropine was given.

Patients-Asthmatic subjects with a diurnal variation in home peak expiratory flow rate of $>20 \%$ for at least $75 \%$ of the time in the two weeks before the study.

Main outcome measures-Peak expiratory flow rate and plasma adrenaline.

Results - Correction of the nocturnal fall in plasma adrenaline at $4 \mathrm{am}$ to resting $4 \mathrm{pm}$ levels did not alter peak expiratory flow rate either before or after parasympathetic blockade with atropine.

Conclusion-A nighttime fall in plasma adrenaline is not a cause of nocturnal asthma.

\section{Introduction}

Measurements of airway calibre vary more from day to night in patients with asthma than in normal subjects, probably as a result of biological day-night rhythms superimposed in the airway inflammation and bronchial hyperresponsiveness that are characteristic of the disease. ${ }^{12} \mathrm{~A}$ large day-night variation in pulmonary function occurs during unstable asthma and may lead to severe nocturnal wheezing or even death. In a previous study we showed that when parasympathetic

nocturnal asthma brochodilatation occurs such that the fall in respiratory function at night is almost completely reversed, implying that increased parasympathetic efferent activity is an important cause of nocturnal asthma. ${ }^{3}$ This also implies, however, that other factors act in addition. These may include circadian rhythms of plasma adrenaline and cortisol, ${ }^{4}$ body temperature, ${ }^{5}$ sleep ${ }^{6} \alpha$ sympathetic nerves, or even dysfunction of non-adrenergic non-cholinergic bronchodilator nerves containing vasoinhibitory peptide. ${ }^{7}$ Circadian changes in airway oedema may also be important.

The role of plasma adrenaline in nocturnal asthma has been studied with two infusion rates of adrenaline at night in five asthmatic subjects. This study showed a reversal of the nocturnal fall in peak expiratory flow rate,${ }^{4}$ but the infusion rates that were used produce a plasma adrenaline concentration at the upper end of the resting daytime physiological range $^{8}$ and therefore the effect of adrenaline was almost certainly overestimated.

We investigated the role of plasma adrenaline in nocturnal asthma. In vitro studies have shown that, in addition to having a direct action on bronchial smooth muscle, adrenaline may modulate parasympathetic nervous activity through prejunctional $\beta_{2}$ receptors, may influence the release of inflammatory mediators from mast cells, ${ }^{4}$ or may alter microvascular leak from blood vessels: ${ }^{10}$

We measured the effect on peak expiratory flow rate of correcting the nocturnal fall in plasma adrenaline within the resting day/night range both before and after blocking parasympathetic efferent activity with atropine. ${ }^{3}$

\section{Method}

In this double blind placebo controlled crossover study we performed two experiments. In the first, 10 asthmatic subjects were studied, each with a diurnal

Physical characteristics of patients (all non-smokers)

\begin{tabular}{|c|c|c|c|c|c|c|}
\hline $\begin{array}{c}\text { Case } \\
\text { No }\end{array}$ & Age & Sex & $\begin{array}{c}\text { Duration } \\
\text { of asthma } \\
\text { (years) }\end{array}$ & Atopy & Drugs & $\begin{array}{l}\text { Peak expiratory } \\
\text { flow rate } \\
\text { (\% predicted) }\end{array}$ \\
\hline \multicolumn{7}{|c|}{ First experiment } \\
\hline $1^{\star}$ & 44 & $\mathrm{~F}$ & 35 & + & $\beta_{2}$ Agonists, anticholinergic drugs, inhaled steroids & 70 \\
\hline $2^{\star}$ & 58 & $\mathrm{~F}$ & 16 & - & $\beta_{2}$ Agonists, anticholinergic drugs, inhaled steroids, theophyllines & 65 \\
\hline $3^{\star}$ & 45 & $\mathrm{~F}$ & 10 & - & $\beta_{2}$ Agonists, anticholinergic drugs, inhaled steroids & 54 \\
\hline $4^{\star}$ & 51 & $\mathbf{F}$ & 25 & - & $\beta_{2}$ Agonists, inhaled steroids, theophyllines & 71 \\
\hline $5^{\star}$ & 39 & M & 25 & + & $\beta_{2}$ Agonists, inhaled steroids, theophyllines & 85 \\
\hline 6 & 50 & $\mathrm{~F}$ & 20 & + & $\beta_{2}$ Agonists, inhaled steroids, theophyllines & 80 \\
\hline 7 & 54 & M & 15 & - & $\beta_{2}$ Agonists, anticholinergic drugs, inhaled steroids, theophyllines & 56 \\
\hline 8 & 23 & $\mathrm{~F}$ & 8 & + & $\beta_{2}$ Agonists, inhaled steroids & 90 \\
\hline 9 & 30 & M & 12 & + & $\beta_{2}$ Agonists, inhaled steroids & 75 \\
\hline 10 & 60 & $\mathrm{~F}$ & 40 & + & $\beta_{2}$ Agonists, anticholinergic drugs, inhaled steroids & 60 \\
\hline \multicolumn{7}{|c|}{ Second experiment } \\
\hline 1 & 48 & M & 35 & - & $\beta_{2}$ Agonists, anticholinergic drugs, theophyllines, inhaled steroids & 49 \\
\hline 2 & 57 & $\mathbf{M}$ & 9 & _ & $\beta_{2}$ Agonists, anticholinergic drugs, theophyllines, inhaled steroids & 39 \\
\hline 3 & 43 & $\mathrm{~F}$ & 30 & - & $\beta_{2}$ Agonists, inhaled steroids & 37 \\
\hline 4 & 54 & M & 5 & - & $\beta_{2}$ Agonists, anticholinergic drugs, theophyllines, inhaled steroids & 33 \\
\hline 5 & 47 & $\mathbf{F}$ & 7 & - & $\beta_{2}$ Agonists, anticholinergic drugs, theophyllines, inhaled steroids & 33 \\
\hline 6 & 64 & F & 2 & - & $\beta_{2}$ Agonists, anticholinergic drugs, theophyllines, inhaled steroids & 38 \\
\hline
\end{tabular}

^Included in second experiment. 